\title{
La ficcionalización de la independencia en dos novelas escritas durante las celebraciones del primer centenario
}

\section{The fictionalization of independence in two novels written during the first centennial celebrations}

Giovanna Pollarolo ${ }^{1}$

\section{Resumen}

Como parte de las celebraciones de 1921-1924, el gobierno del presidente Leguía convocó el Concurso del Centenario de la Batalla de Ayacucho en las áreas de poesía y novela. Tiempos de la patria vieja. Novela histórica de Angélica Palma (Lima, 1878-1935) y Por la estirpe. Novela colonial de José Félix de la Puente (Trujillo, 1882-1959) fueron las ganadoras. Prestando atención al relato de ciertos hechos, personajes y la trama amorosa, en este trabajo analizo las representaciones discursivas del proceso independentista que construyeron ambas novelas después de los primeros cien años de declarada la independencia. Me interesa mostrar cómo, a contracorriente de la historia oficial, esas novelas dan cuenta de la memoria de la independencia como una guerra civil, dolorosa y desgarrada.

1 Docente de la Sección Lingüística y Literatura de la Facultad de Letras y Ciencias Humanas de la Pontificia Universidad Católica del Perú. Correspondencia (Corresponding author): pollarologiovanna@gmail.com; Código ORCID: 0000- 0002 - 3209 - 9899 
La ficcionalización de la independencia en dos novelas escritas durante las celebraciones del primer centenario

Palabras clave: Centenario de la independencia del Perú, historia oficial, memoria colectiva, memorias subterráneas

\section{Abstract}

As part of the celebrations of 1921-1924, the government of President Leguía called the Contest for the Centennial of the Battle of Ayacucho in the areas of poetry and novels. Tiempos de la patria vieja. Novela histórica by Angélica Palma (Lima, 1878-1935) and Por la estirpe. Novela colonial by José Félix de la Puente (Trujillo, 1882-1959) were the winners. Paying attention to the narration of certain events, characters and especially the love plot, in this paper, I analyze the discursive representations of the independence process built by both novels after the first hundred years of the declaration of the Peruvian independence. I am interested in showing how, contrary to the official history, these novels give an account of the memory of the independence as a painful and torn civil war.

Key words: Centennial of the independence of Peru, official history, collective memory, underground memories

\section{Introducción}

Siguiendo las reflexiones de Pierre Vilar acerca de la conme-

348 moración de la publicación del Quijote, Carlos Contreras y Luis Miguel Glave en su estudio introductorio a La independencia del Perú ¿Concedida, conseguida, concebida? proponen que los centenarios sirven para recordarnos que los grandes hechos y las grandes obras tienen una fecha, es decir, responden "a unas circunstancias históricas específicas, fuera de las cuales su comprensión podría distorsionarse"; pero la comprensión de tales circunstancias, así como el significado de los grandes hechos "va cambiando de generación en gene- 
ración" (2015, p. 14). En el Perú, la conmemoración de su independencia se inicia con el arribo del general José de San Martín, quien la declara el 28 de julio del 1821: "El Perú es libre e independiente por la voluntad general de los pueblos" y culmina con la campaña libertadora liderada por el general Simón Bolívar y la derrota del ejército realista en Ayacucho en 1824.

La manera de recordar el bicentenario remite al centenario: cómo se celebró, qué discursos y reflexiones se construyeron en torno la primera centuria, qué se discutía, cuáles eran las preocupaciones de la sociedad de entonces. ${ }^{2}$ A diferencia del bicentenario, marcado por crisis de toda índole ${ }^{3}$ que invitan

2 Estas interrogantes, sin duda, son muy generales y no es el objetivo de este trabajo responderlas. Solo me referiré al contexto general de las celebraciones.

3 La crisis política que comenzó con la renuncia del presidente Pedro Pablo Kuczynski, la asunción del mando de su segundo vicepresidente, Martin Vizcarra, el 23 de marzo de 2018, y su vacancia votada por el Congreso el 9 de noviembre de 2020, y la crisis sanitaria y económica causada por la pandemia del coronavirus, marcará, ya la marcó, sin duda alguna, la memoria del bicentenario. El Proyecto Especial Bicentenario de la Independencia del Perú, creado en 2018, publicó el libro digital 25 ensayos desde la pandemia para imaginar el Perú bicentenario con la urgencia de pensar el futuro en este presente, en el que un mal inesperado desnudó las carencias e inequidades de nuestra República: “¿Quién está de ánimo para celebrar en medio de una emergencia sanitaria los doscientos años de una república agrietada que hace agua por todos lados? Considerando nuestro sistema de salud, a punto de colapsar, y una pobreza que avergüenza, ¿somos realmente treinta millones de hombres y mujeres libres? ¿Gozamos todos de la "dignidad republicana" a la que se refirió alguna vez Faustino Sánchez Carrión? se preguntó la historiadora Carmen Mc Evoy en dicho libro (p. 15). Meses después, y aún en emergencia sanitaria, se desencadenó la crisis política con la declaratoria de vacancia del presidente Martín Vizcarra, el nombramiento de Manuel Merino como presidente y su renuncia cinco días después, tras una intensa jornada de 
La ficcionalización de la independencia en dos novelas escritas durante las celebraciones del primer centenario

a la reflexión, crítica y autocrítica, el centenario fue celebrado como un hecho glorioso y heroico. Deseada y conseguida por la mayoría de peruanos que lucharon arduamente para conseguir la expulsión de los españoles, el éxito de la gesta independentista merecía ser recordado: la nación fundada cumplía 100 ańos y el gobierno del dictador Augusto B. Leguía se empeńó en que el aniversario fuera celebrado con gran pompa y derroche. Hizo de Lima una fiesta, según cuentan los historiadores y los diarios de entonces: inauguración de edificios y grandes monumentos, instalación de luz eléctrica, construcción de grandes avenidas, presidentes y embajadores invitados, banquetes, retretas en calles y plazas. Los festejos parecían anunciar un país rico y próspero y la promesa de la "Patria Nueva" en la que muchos creyeron, parecía una realidad. En 1921, nadie quería recordar las guerras civiles de la primera centuria, los conflictos políticos, sociales y económicos, los abismos culturales, la derrota frente a Chile.

Como parte de esas apoteósicas celebraciones de 1921-1924, y aunque pasó desapercibido en medio de la algarabía general -interminables y masivas fiestas, recibimiento de autoridades de países amigos, ceremonias oficiales, desfiles- el gobierno del presidente Leguía convocó el Concurso del Centenario de la Batalla de Ayacucho en las áreas de poesía y novela. El jurado de novela, conformado por Luis Varela y Orbegoso, Juan B. de Lavalle y Luis Alberto Sánchez, de acuerdo con una información publicada el 6 de diciembre de 1924 en El Comercio, dio ganador a José Félix de la Puente (Trujillo, 1882-1959) con su novela Por la estirpe. Novela colonial; y el segundo a Tiempos de la patria vieja. Novela histórica de Angélica Palma (Lima, 1878-1935).

protestas populares que fueron reprimidas con violencia. En ese contexto y en medio de la campańa electoral, el proyecto del bicentenario perdió visibilidad y presencia. Este será, sin duda, el contexto que construirá la memoria de las generaciones futuras. 
Por razones que precisan ser investigadas, la novela ganadora, que debió ser publicada por el Estado, tuvo que esperar hasta 1957, año en que apareció con el sello de la Editorial Ausonia. En la "Nota de los editores" se señala Por la estirpe, "ganadora del Primer Premio del Concurso Literario del Centenario de la Batalla de Ayacucho" y cuya publicación es "Un imperativo de justicia al mérito y a la vez de cumplimiento de un deber patriótico": mérito a la obra y al autor; y cumplimiento a una promesa incumplida, ya que esa novela "debió ser publicada por el Estado, conforme lo dispuso expresamente la Resolución Suprema del 26 de diciembre de 1924" (párrafo 1).

Además de la dedicatoria "Para el doctor Raúl Porras Barrenechea, insigne historiador y hombre de letras", y la "Nota de los editores", la publicación incluye un prólogo de Luis Alaiza (sic) y Paz Soldán que empieza, justamente, reclamando con sutil elegancia la injusticia cometida:

No voy a recordar que la parte práctica de los premios no llegó a cogerla, porque, no obstante haber transcurrido un cuarto de siglo, el veredicto del jurado quedó incumplido por la autoridad, en su parte económica. Mejor es silenciar esto para no desprestigiarnos y, por otra parte, ello importa poco. Lo positivo es que José Félix triunfaba (De la Puente, 1957, prólogo, párrafo 1).

La novela de Angélica Palma, que de acuerdo con la nota citada de El Comercio mereció el segundo premio, fue publicada en Buenos Aires por la editorial Nuestra América en 1926 y, curiosamente, se señala que "Esta obra obtuvo el primer premio del concurso de novelas históricas del Centenario de Ayacucho, celebrado en Lima, Perú, 1924”.

Más allá de la desinformación en torno al concurso, que evidencia la poca transparencia que caracterizó al régimen leguiísta, me interesa analizar las representaciones discursivas del proceso independentista que construyen ambas novelas 
La ficcionalización de la independencia en dos novelas escritas durante las celebraciones del primer centenario

100 años después, que estuvieron marcados, reitero, por la inestabilidad política, las guerras civiles y el desastre de la derrota frente a Chile, que el gobierno de Leguía pretendió ignorar y olvidar con los apoteósicos festejos.

Partiendo de la premisa de que las tramas ficcionales informan sobre la realidad, la representan, filtran, interpretan, reelaboran o la transgreden, mi propósito es estudiar las construcciones narrativas de las novelas ganadoras del concurso con el fin de mostrar cómo mediante el relato de ciertos hechos, personajes y sobre todo de la trama amorosa, ambas representan la gesta independentista como una guerra civil, dolorosa y desgarrada, que contrasta con el discurso heroico de una guerra de liberación nacional en la que los bandos, los realistas de un lado y los patriotas del otro, estaban marcadamente definidos, tal como lo construyó la historia oficial y se instaló en la "memoria colectiva" ${ }^{4}$ Veremos cómo estas representaciones ficcionales escritas durante los ańos de las celebraciones de la primera centuria se anticiparon a las nuevas propuestas de la historiografía contemporánea.

De acuerdo con la historiografía oficial, el proceso de la emancipación fue una guerra de liberación nacional que comenzó "en el momento mismo de la Conquista con la unión de la experiencia espańola con la indígena y el mestizaje cultural" (Sobrevilla, 2015, p. 403). La gesta independentista y su lucha por la libertad se inició con el levantamiento de Túpac Amaru y prosiguió con movimientos insurgentes en la sierra sur que culminaron exitosamente con el arribo de los ejércitos patriotas de San Martín, quien declaró la independencia del Perú en 1821; y luego con Bolívar que la consoli-

4 Entiendo la "memoria colectiva" como aquella que se forja y estructura en función de una serie de "puntos de referencia", en términos de Halbwachs (1968), y que son comunes a un grupo; a su vez, los diferencia de los demás y determina su pertenencia a dicho grupo. 
dó en 1824. Benjamín Vicuña Mackenna en La Revolución de la Independencia en el Perú escrita en 1860 fundó, en cierto modo, el discurso de la independencia peruana dotándolo de héroes y acciones épicas que demostraban la participación activa de los peruanos, que intelectuales y políticos vecinos habían negado.

Es decir, el discurso independentista fue estableciendo los "puntos de referencia": monumentos, fechas conmemorativas, personajes históricos, batallas, música, etcétera, que en términos de Maurice Halbwachs "estructuran nuestra memoria y la insertan en la memoria de la colectividad a la que pertenecemos" (Pollack, 2006, p. 17). Así, la "memoria colectiva" de la independencia se consolidó como un hecho glorioso y heroico en el que los patriotas triunfaron, fundaron la nación peruana y expulsaron a los españoles invasores. Deseada y conseguida por los peruanos, el primer centenario de la gesta heroica debía ser celebrado con gran pompa. Incluyó no solo fiestas y desfiles, sino, como se ha visto, un concurso de novela y otro de poesía con temática independentista.

La celebración del sesquicentenario, en cambio, estuvo marcada por la tesis presentada por los historiadores Heraclio Bonilla y Karen Spalding, quienes sostuvieron que esta fue "concedida", no solo porque se obtuvo gracias a la participación de ejércitos extranjeros, sino porque nadie la deseaba, tesis que atacó una de las bases más sólidas del nacionalismo oficial peruano e inició un largo debate. La nueva nación, como advierte Sobrevilla, no se construyó "sobre la base de una narrativa triunfante de la independencia" (p. 2015, p. 400) y así fue ganando fuerza la interpretación según la cual las élites limeñas tardaron en involucrarse en el proyecto libertador, cambiaron de bando más de una vez y sus disputas generaron nuevos enfrentamientos que crearon un clima de inestabilidad y, en muchos casos, nostalgia por el viejo or- 
La ficcionalización de la independencia en dos novelas escritas durante las celebraciones del primer centenario

den, mientras algunos sectores de las clases populares asistían impasibles al enfrentamiento entre los ejércitos realistas y patriotas.

Hacia finales del siglo XX empezó a desarrollarse una visión de la Independencia alejada de la gesta heroica decimonónica, pero también de aquella que la calificó como "concedida" y como un hecho político resultado del vacío de poder dejado por la renuncia de Fernando VII, lo que fue modelando "nuevos valores y sentimientos en la cultura política de los peruanos" (Contreras y Glave, 2015). Citando a Tomás Pérez Vejo, Contreras y Glave, sintetizan esta nueva visión de la Independencia desde la historiografía:

Las guerras de independencia no responden a lo que entendemos como guerras de liberación nacional, guerras en las que una nación lucha por independizarse de otra. En sentido estricto no son ni siquiera guerras de independencia sino más bien lo que hoy entenderíamos como guerras civiles, en las que una sociedad se ve desgarrada por la existencia de proyectos alternativos e incompatibles de organización económica, social o política. (p. 10)

Aun cuando el discurso explícito de las novelas ganadoras, tanto Por la estirpe como Tiempos de la patria vieja, evidencia una intención celebratoria del centenario en sintonía con la memoria colectiva de la gesta independentista, la trama ficcional, específicamente las historias de amor que desarrollan, entre otros aspectos que se verán luego, dan cuenta de esta reciente aproximación historiográfica que recupera, sin duda alguna, memorias que quedaron ocultas, que fueron silenciadas por la "memoria colectiva". Las novelas que ganaron el concurso, pero que no fueron publicadas como lo establecía la convocatoria, se sirven de la ficción para recuperar la memoria de la Independencia como una guerra civil, dolorosa y desgarrada que dividió y enfrentó a las familias, esposos de esposas, padres de hijos en una disputa irreconciliable. 


\section{Por la estirpe. Novela colonial de José Félix de la Puen- te, 1882-1959}

Los acontecimientos de Por la estirpe se desarrollan en Lima en vísperas del arribo del Libertador y, como lo había establecido la historia oficial, confronta el entusiasmo y expectativas del pueblo, representados por los personajes buenos y heroicos, con la resistencia de la nobleza personificada en la trama folletinesca por el marqués de Alcántara y su esposa. El ánimo patriota es exaltado y la narración se organiza desde una perspectiva que simpatiza con la causa independentista. Así, quienes están en contra de la causa son caricaturizados, como ocurre con el notario Hilario de Gonzaga, un criollo que desprecia a los rebeldes y se siente noble porque su ama de leche fue la marquesa de Alcántara. «Más realista que el rey», debería ser republicano por su "tez oscura», comentan los personajes patriotas que esperan con ansias la llegada de San Martín, que implantará la igualdad entre todos: «No habrá señor conde ni pipirigańas de la laya. Nos hablaremos todos de tú como en Francia» (De la Puente, 1957, p. 37), le dice un personaje que simpatiza con la causa al viejo notario.

La historia de amor se presenta como imposible mientras no triunfe la gesta emprendida por don José de San Martín, el Libertador. El romance, eje del relato, entre Encarnación, la hija del marqués y «Sebastián sin nombre», llamado así por su persistencia en negar su «origen bastardo» solo será posible cuando San Martín libere a la patria: dará una ley que limite la nunca antes discutida autoridad del padre y libere a los hijos de la sumisa obediencia a la que estaban condenados por el orden colonial. Encarnación tiene un sueño: San Martín ingresa con Sebastián al gabinete del marqués y le dice con solemne voz: «Señor Marqués, inútil será que neguéis vuestro asentimiento. Sebastián y Encarnación, vuestra graciosa hija, se aman. La ley les protege y [...] vos no sabéis lo que es la ley de la libertad. La potestad paterna tiene ahora límites». 
La ficcionalización de la independencia en dos novelas escritas durante las celebraciones del primer centenario

Sebastián se alegra ante tan hermoso sueño: «Ese sueño será realidad un día, te lo juro. Mi nombre [...] algún día tendré alguno [...] será grande, y entonces, cuando la Patria ahuyente las preocupaciones de la aristocracia, podrás ser mi esposa». Arrobada, convertida súbitamente en patriota, Encarnación afirma: «Ay, solo tengo esperanzas en ese San Martín». «Pero no vayas a creer que se trata de un santo, de uno de tus santos cristianos», ironiza Sebastián. Para Encarnación sí es un santo; solo un santo puede "hacer el milagro de nuestro amor» (De la Puente, 1957, pp. 76-77); es decir, de unir a un patriota con una española; a una noble con un bastardo. Informado de los amores de su hija, el marqués la obliga a ingresar al convento para impedir su unión; y Sebastián se incorpora al ejército patriota. Participa activamente en la lucha independentista, forma parte del ejército libertador de San Martín que declara la independencia y del de Bolívar que expulsa a los últimos españoles luego de las batallas de Junín y Ayacucho. Sebastián regresa triunfante, ahora sí con nombre y apellido dignos, ciudadano de la nación recién fundada. Legitimado socialmente, busca a Encarnación para casarse y cumplir su sueńo de unión eterna, que ella ahora rechaza: «Mi alma se ha ido transformando... Soy un alma y nada más. Tu Encarnación murió». El marqués, desesperado al ver a su hija en ese estado, aprueba la unión con el joven patriota, pero ella permanece ensimismada en su propio monólogo, víctima de la intolerancia y del autoritarismo del padre; víctima, en suma, cual alegoría de la guerra independentista, de la irremediable fractura social.

Así, la gesta independentista en Por la estirpe se narra como un hecho dramático, doloroso y sin final feliz en tanto que enfrenta a un padre con su hija; él, por ser español y noble rechaza a los patriotas; la hija, criolla nacida en Lima, se vuelve patriota por amor a Sebastián, un joven noble pero no reconocido por su padre, el virrey, debido a que fue concebido fuera del matrimonio; es decir, ajeno a la metrópoli. 
Los escritores fundacionales que ilustran la propuesta de Doris Sommer, ${ }^{5}$ la unión de una pareja como alegoría de la nación propia de los romances del XIX, hubieran hecho posible el matrimonio de Encarnación y Sebastián; pero la alianza entre la aristocracia española y los criollos representados como bastardos se vislumbra aquí como imposible, aun cuando se haya descubierto que Sebastián era hijo del virrey, aun cuando el aristócrata marqués se vea obligado a consentir la unión. El hogar del marqués queda destruido al perder a su hija y Sebastián es condenado a la soledad. Es decir, los sectores en pugna, criollos de un lado y realistas del otro, no logran limar sus diferencias ideológicas pese a pertenecer al mismo grupo social una vez desvelado el origen noble de Sebastián.

\section{Tiempos de la patria vieja. Novela histórica de Angélica Palma, 1878-1935}

En La patria vieja de Angélica Palma, la Independencia es percibida como una guerra civil de manera totalmente explícita, como se verá en seguida. La novela se inicia con la

5 "Las novelas románticas se desarrollan mano a mano con la historia patriótica de América Latina. Juntas despertaron un ferviente deseo de felicidad doméstica que se desbordó en sueños de prosperidad nacional materializados en proyectos de construcción de naciones que invistieron a las pasiones privadas con objetivos públicos» (Sommer, 2004). Desde esa perspectiva y de acuerdo con Sommer, las historias de amor hacen posible la construcción de un futuro; historias en las que la fuerza del amor permite limar las diferencias, apostar por la conciliación entre dos grupos irreconciliables sea por razones políticas, religiosas, económicas, sociales, raciales. La pareja, en Sommer, alegoriza la viabilidad de una nación que, para ser tal, requiere de una conciliación entre sectores en pugna que cada miembro representa. "Con un final feliz, o sin él, los romances invariablemente revelan el deseo de jóvenes y castos héroes por heroínas igualmente jóvenes y castas: la esperanza de las naciones en las uniones productivas» (p. 41). 
La ficcionalización de la independencia en dos novelas escritas durante las celebraciones del primer centenario

descripción de un cuadro familiar en el que todos los miembros participan en el rezo del santo rosario: el padre, Rodrigo Hinostroza "noblote y testarudo como legítimo castellano»; la madre, Rosa Centeno, criolla bastante más joven que él; la abuela, madre de Rosa, también criolla; y los dos jóvenes hijos de la pareja, Rosario y Fernando. Parece reinar la armonía fundada en el amor filial, los valores cristianos de amor a Dios, a la madre patria y a los padres. Cuando don Rodrigo pide rezar «Un padre nuestro y un ave maría para que vuelva la paz a este desventurado país con el triunfo completo de nuestro rey y señor", la voz narrativa pregunta "¿Se unieron a la oración todos los presentes?» (1926, p. 10). La pregunta destruye la idílica escena; pronto sabremos que oculta miedos, tensiones, secretos, mentiras e incluso odio; sentimientos que padece la sociedad entera inmersa en una guerra política en la que los contendientes se disputan el poder. Esa noche, el hijo adolescente finge acostarse y cuando sus padres están dormidos abandona la casa para dirigirse a la reunión de un grupo de patriotas que conspira contra el virrey. Rosario, la hija, recibe una carta de su amado, el patriota Aguilera, quien ha invitado a Fernando a la reunión clandestina: "Se va a encender la guerra civil en casa», vaticina el patriota enamorado de Rosario. "Ya está encendida» (p. 34), afirma el joven Fernando ansioso de ser aceptado en las filas del ejército que se dirige a la sierra a combatir a De la Serna y Canterac. Su madre y su abuela son tan patriotas como él y Rosario. El padre, en cambio, es descrito como un español rancio, absolutista, "tirano más cruel y aborrecible que Fernando VII" (p. 108). Y Aguilera, firme patriota, es hijo de un fallecido militar andaluz que combatió contra la revuelta de Aguilar y Ubalde en Huamanga. Cuando quedó huérfano, viajó a España, pero allí se sintió desarraigado y en el ambiente liberal que reinaba en esos años adoptó la causa patriótica. Volvió al Perú en 1820 para unirse al ejército libertador. Antes de que viajara a España, Hinostroza lo consideraba un buen partido para su hija, pero a su vuelta comprobó rápidamente que ha- 
bía sido "contagiado por las corrientes perniciosas que están dando al traste con este país y al fin lo arrastrarán al abismo» (p. 74). Y prohibió que ingresara a su casa.

El drama se desencadena cuando Hinostroza descubre que su hijo ha abrazado la causa libertadora con la complicidad de Rosario. Ofendido al constatar que su propia familia lo ha traicionado, se enrola en el ejército realista a pesar de su avanzada edad. En esa sección, se evidencia la visión de la lucha independentista como una guerra civil antes que la lucha de los patriotas contra sus opresores para lograr la liberación nacional. El 9 de diciembre, antes de iniciarse la batalla de Ayacucho, los generales de ambos bandos acuerdan conceder una breve tregua a fin de que amigos y familiares que militan en bandos contrarios se reúnan y «disfruten de un momento de afectuosa expansión». Fernando se dirige a la línea neutral en busca de su padre, pero este no acude al encuentro. Finalizada la batalla y derrotado el ejército realista, la novela narra el hecho histórico en el que el general Sucre pacta la capitulación que el ejército español le propone por intermedio del teniente general de los Reales Ejércitos de Su Majestad Católica, don José de Canterac. Por ese pacto, quedan libres todos los prisioneros y el Estado peruano se compromete a facilitar el transporte de quienes deseen abandonar el país, a apoyarlos económicamente hasta su partida guardándoseles la debida consideración. Asimismo, les concede el derecho a disponer de sus bienes y propiedades, y a radicar en la República sin ser incomodado por sus pasadas opiniones. Tras la firma de tan generoso pacto, Sucre y sus generales invitan a sus pares españoles a un almuerzo en Quinua, donde acude también Hinostroza. «Muchos casos de parientes próximos combatiendo en filas opuestas se han visto en esta guerra", comenta un general. Y Sucre responde: «Hemos luchado entre conocidos». Sorprendidos todos del silencio de Hinostroza, tratan de convencerlo de que vea a su hijo Fernando, quien ha sido herido. Acabe con esta comedia, dice un gene- 
La ficcionalización de la independencia en dos novelas escritas durante las celebraciones del primer centenario

ral, aludiendo a la necesidad de perdonar y olvidar. A lo que Hinostroza responde con un dramático discurso que visibiliza las fracturas y desgarros de la guerra: “iComedia no! por una comedia no me vería yo, viejo y solo, lejos de mi casa y de los míos, que ya ni siquiera sé si son míos. Por una comedia no habría combatido contra mi propio hijo. No habría permanecido hoy mudo, mordiendo las palabras que querían escapárseme a preguntar si este hijo vive o si misma bala lo mató. Comedia no, tragedia horrible que acaba con las ideas, con los sentimientos, con todo» (p. 142).

El relato de la ruptura de una familia, cuyos miembros la viven de manera dolorosa y desgarrada a causa de la guerra independentista que separa padres de hijos, marido y mujer, hermanos, parientes y amigos bien puede ser vista como alegoría de los enormes costos en vidas humanas, expropiaciones y destrucción de riquezas que acarreó la guerra independentista, así como de las divisiones entre pueblos con los que antes se habían mantenido vínculos sociales, afectivos, comerciales. Esa es una lectura que está más cerca de las interpretaciones historiográficas actuales que de las decimonónicas que construyeron la memoria colectiva y animaron las celebraciones del primer centenario.

Tal vez sea esa la razón por la cual los ganadores del concurso promovido por el Supremo Gobierno en conmemoración del centenario de Ayacucho no recibieron nunca su premio; tal vez por eso el gobierno tampoco cumplió su compromiso de publicarlas conforme lo dispuso la Resolución Suprema del 26 de diciembre de 1924. Angélica Palma, a quien algunos críticos acusaron de simpatizar con la ideología hispanista, la publicó en Buenos Aires en 1926; José Félix de la Puente debió esperar hasta 1957.

Más allá de estas suposiciones, ambas novelas dan cuenta, como se ha visto, de un proceso independentista vivido do- 
lorosamente y de una memoria negada por la historia oficial construida ante la necesidad de crear una identidad nacional a partir de un patriotismo que pretendió olvidar o ignorar las grandes brechas, inequidades y diferencias que hasta hoy, 200 años después, siguen vigentes e impiden consolidar un proyecto de nación, construir un acuerdo, un nuevo pacto social, una visión común.

Recibido: 16 de agosto del 2020

Aprobado: 15 de marzo del 2021

\section{Referencias bibliográficas}

Bonilla, H. y Spalding, K.

(2015) La Independencia en el Perú: las palabras y los hechos. En C. Contreras y L. M. Glave (Eds.), La independencia del Perú: ¿Concedida, conseguida, concebida? (pp. 39-73). Lima: Instituto de Estudios Peruanos.

Contreras, C. y Glave, L. M. (Eds.)

(2015) La independencia del Perú ¿Concedida, conseguida, concebida? Lima: Instituto de Estudios Peruanos.

Contreras, C. y Glave, L. M. (Eds.)

(2015) Estudio introductorio. En La independencia del Perú ¿concedida, conseguida, concebida? (pp. 9-31). Lima: Instituto de Estudios Peruanos.

Halbwachs, M.

(1968) La mémoire collective. Paris: Presses Universitaires de France. 
La ficcionalización de la independencia en dos novelas escritas durante las celebraciones del primer centenario

McEvoy, C.

(2020) Bicentenario republicano: dolor, resiliencia y esperanza. En Proyecto Especial Bicentenario de la Independencia del Perú, 25 ensayos desde la pandemia para imaginar el Perú bicentenario (pp. 15-20). Lima: Perú Bicentenario. https://drive.google.com/ file/d/1DJlT8eyt5xT8gTB-NNPoSUIbPtb8UAv2/ view

Palma, A.

(1926) Tiempos de la patria vieja. Novela histórica. Buenos Aires: Ed. Nuestra América.

Pollack, Michael

(2006) Memoria, olvido, silencio. La producción social de identidades frente a situaciones límites. La Plata: Al Margen, 2006.

Puente, J. F. de la

Por la estirpe. Novela colonial. Lima: Ed. Ausonia, S.A. $146 \mathrm{p}$.

Sobrevilla, N.

La nación subyacente: de la monarquía hispánica al Estado en el Perú. En C. Contreras y L. M. Glave (Eds.), La independencia del Perú: ¿Concedida, conseguida, concebida? (pp. 39-73). Lima: Instituto de Estudios Peruanos.

Sommer, D.

(2004) Ficciones fundacionales: Las novelas nacionales de América Latina. México: Fondo de Cultura Económica. 